\title{
Strain, Soil-Type, Irrigation Regimen, and Poultry Litter Influence Salmonella Survival and Die-off in Agricultural Soils
}

\author{
Cameron A. Bardsley', Daniel L. Weller ${ }^{2}$, David T. Ingram ${ }^{3}$, Yuhuan Chen ${ }^{3}$, David Oryang ${ }^{3}$, \\ Steven L. Rideout ${ }^{4}$ and Laura K. Strawn ${ }^{1 *}$ \\ 'Department of Food Science and Technology, Eastern Shore Agricultural Research and Extension Center, Virginia Tech, \\ Painter, VA, United States, ${ }^{2}$ Department of Environmental and Forest Biology, SUNY College of Environmental Science and \\ Forestry, Syracuse, NY, United States, ${ }^{3}$ Center for Food Safety and Applied Nutrition, US Food and Drug Administration, \\ College Park, MD, United States, ${ }^{4}$ School of Plant and Environmental Sciences, Eastern Shore Agricultural Research and \\ Extension Center, Virginia Tech, Painter, VA, United States
}

The use of untreated biological soil amendments of animal origin (BSAAO) have been identified as one potential mechanism for the dissemination and persistence of Salmonella in the produce growing environment. Data on factors influencing Salmonella concentration in amended soils

OPEN ACCESS

Edited by: Riadh Hammami, University of Ottawa, Canada

Reviewed by:

Ade Oladeinde, United States Department of Agriculture, United States Tawni L. Crippen, United States Department of Agriculture, United States

${ }^{*}$ Correspondence: Laura K. Strawn Istrawn@vt.edu

Specialty section: This article was submitted to Food Microbiology,

a section of the journal Frontiers in Microbiology

Received: 31 July 2020 Accepted: 29 January 2021 Published: 16 March 2021

Citation: Bardsley $C A$, Weller DL, Ingram DT, Chen Y, Oryang D, Rideout SL and Strawn LK (2021) Strain, Soil-Type, Irrigation Regimen, and Poultry Litter Influence Salmonella Survival and Die-off in Agricultural Soils.

Front. Microbiol. 12:590303. doi: 10.3389/fmicb.2021.590303 are therefore needed. The objectives here were to (i) compare die-off between 12 Salmonella strains following inoculation in amended soil and (ii) characterize any significant effects associated with soil-type, irrigation regimen, and amendment on Salmonella survival and die-off. Three greenhouse trials were performed using a randomized complete block design. Each strain ( $4 \log \mathrm{CFU} / \mathrm{g})$ was homogenized with amended or non-amended sandy-loam or clay-loam soil. Salmonella levels were enumerated in $25 \mathrm{~g}$ samples 0, 0.167 (4 h), 1, 2, 4, $7,10,14,21,28,56,84,112,168,210,252$, and 336 days post-inoculation (dpi), or until two consecutive samples were enrichment negative. Regression analysis was performed between strain, soil-type, irrigation, and (i) time to last detect (survival) and (ii) concentration at each time-point (die-off rate). Similar effects of strain, irrigation, soil-type, and amendment were identified using the survival and die-off models. Strain explained up to $18 \%$ of the variance in survival, and up to $19 \%$ of variance in die-off rate. On average Salmonella survived for 129 days in amended soils, however, Salmonella survived, on average, 30 days longer in clay-loam soils than sandy-loam soils [95\% Confidence interval $(C l)=45,15]$, with survival time ranging from 84 to 210 days for the individual strains during daily irrigation. When strainspecific associations were investigated using regression trees, $S$. Javiana and $S$. Saintpaul were found to survive longer in sandy-loam soil, whereas most of the other strains survived longer in clay-loam soil. Salmonella also survived, on average, 128 days longer when irrigated weekly, compared to daily $(\mathrm{Cl}=101,154)$, and 89 days longer in amended soils, than non-amended soils $(\mathrm{Cl}=61,116)$. Overall, this study provides insight into Salmonella survival following contamination of field soils by BSAAO. Specifically, Salmonella survival may be strainspecific as affected by both soil characteristics and management practices. These data can assist in risk assessment and strain selection for use in challenge and validation studies.

Keywords: Salmonella, irrigation, time to harvest interval, biological soil amendments of animal origin, strain variability, survival, poultry litter, die-off rate 


\section{INTRODUCTION}

Past reports estimate that Salmonella is the leading cause of bacterial foodborne disease outbreaks linked to fresh produce in the United States (US) and Europe (Hanning et al., 2009; Callejón et al., 2015). Fruits and vegetables are particularly problematic as an etiological vehicle due to the lack of a kill step between harvest and consumption that would eliminate or reduce pathogen loads. Thus, there is particular interest in preventing Salmonella contamination of fresh produce, including in the pre-harvest environment. As illustrated by past Salmonella outbreaks in Delaware, and the eastern shore of Maryland and Virginia (i.e., the Delmarva; Greene et al., 2008; Hanning et al., 2009; Painter et al., 2013; Bell et al., 2015; CDC, 2016; Gu et al., 2018; Truitt et al., 2018), there are multiple mechanisms whereby produce can be contaminated in the farm environment. In response to the aforementioned outbreaks, multiple studies investigated potential sources of the outbreak serovar in the Delmarva, and identified wildlife (Gruszynski et al., 2014), irrigation water (Greene et al., 2008; Hanning et al., 2009), and the use of biological soil amendments of animal origin (BSAAO) as potential Salmonella sources (CDC, 2016; $\mathrm{Gu}$ et al., 2019). Moreover, studies in other produce-growing regions (e.g., California, New York, and Florida) have also detected Salmonella in agricultural field soils (Gorski et al., 2011; Strawn et al., 2013a,b, 2014; Bell et al., 2015), irrigation water (McEgan et al., 2013; Cooley et al., 2014; Weller et al., 2015, 2020), and BSAAOs (Gu et al., 2019). As such, preventing pre-harvest produce contamination is a priority for industry and public health professionals.

Since the pre-harvest environment represents a key route for Salmonella contamination of fresh produce, understanding pathogen ecology in pre-harvest environments, including factors affecting pathogen survival and growth, is key to developing effective food safety risk mitigation strategies. For example, past studies (Chandler and Craven, 1980; Danyluk et al., 2007; Underthun et al., 2018; Jechalke et al., 2019) have suggested that Salmonella can survive for long periods in soils and survival was dependent on soil characteristics (e.g., moisture, composition, and temperature). Specifically, the use of BSAAOs appears to facilitate Salmonella survival (Baloda et al., 2001; Holley et al., 2006; You et al., 2006; Nyberg et al., 2010; Ongeng et al., 2011; Hruby et al., 2018; Shah et al., 2019). For example, a study conducted in Iowa (Hruby et al., 2018) detected Salmonella in soil samples collected from plots amended with poultry litter approximately 1 year after BSAAO application. Similarly, a study (You et al., 2006) recovered Salmonella from bovine manure-amended soils 332 days after application in the laboratory (controlled temperature and moisture). These findings are concerning from a food safety stand-point because Salmonella in soils contaminated by BSAAO can transfer to the harvestable portion of crops (Natvig et al., 2002; Islam et al., 2004a,b; Franz et al., 2005; Kenney et al., 2006; Oni et al., 2015; Kumar et al., 2017). Cessation of BSAAO application to meet food safety concerns is impractical since BSAAOs, such as poultry litter, are economical, organic fertilizers whose application promotes soil health and fertility (Watts et al., 2010; Gu et al., 2019). As such, additional research is needed to better understand Salmonella dynamics following BSAAO amendment, and provide growers with specific guidance on how to best manage food safety hazards in BSAAOs.

Recognizing the food safety risks associated with as well as the economic importance of BSAAOs, stakeholders have developed recommendations on intervals between application of untreated BSAAO and harvest. For example, the United States Department of Agriculture (USDA) National Organic Program recommends intervals of at least 120 days between manure application and harvest if the edible/ harvestable portion of the produce has direct contact with the soil (USDA, 2015, 2020). However, it is unclear (i) if existing data support the National Organic Program guidelines and (ii) if a one-size-fits all guideline is appropriate for all commodities, management practices (e.g., type of BSAAO used and irrigation regimen), produce-growing regions, and even fields within a single operation. Indeed, past studies have shown that soil characteristics, environmental and laboratory conditions (e.g., temperature), and amendment type can all affect Salmonella survival in soil (Himathongkham et al., 1999; You et al., 2006; Semenov et al., 2009; Ramos et al., 2019). Similarly, past studies (Strawn et al., 2014; Weller et al., 2015; Sharma et al., 2020) indicates that factors that vary between produce-growing regions, between farms within the same region, and between fields on the same farm can affect pathogen dynamics in farm environments.

Furthermore, a large variety of Salmonella strains has been identified in different types of manure, including poultry manure (Elgroud et al., 2009; Alali et al., 2010; Chinivasagam et al., 2010; Donado-Godoy et al., 2012; Jay-Russell et al., 2018a,b). For example, one study (Alali et al., 2010) identified 70 different strains of Salmonella in seven broiler poultry farms. Another study (Jay-Russell et al., 2018b) reported that, among 66 Salmonella isolates from untreated poultry manure samples obtained in the western US over a year, whole genome sequencing data showed 12 Salmonella serotypes or serotype clusters. While several studies (Franz et al., 2008, 2011) performed in laboratory settings, using cattle manure-amended soil, showed substantial variability of survival of Escherichia coli O157:H7 strains of human or animal origins, data are lacking on the variability in survival of different Salmonella strains in soil amended with poultry manure. Additionally, recent studies (Andino and Hanning, 2015; Harrand et al., 2019) have shown that differences between pathogen strains can result in substantially different responses to environmental stresses. As such, the study reported here was performed to (i) investigate survival and die-off between 12 Salmonella strains following inoculation in poultry litter amended soil, and (ii) characterize the effect of soil-type (sandy-loam vs. clay-loam), irrigation regimen (daily vs. weekly), and amendment (poultry litter vs. non-amended) on Salmonella survival and die-off of a selection of 12 strains. 


\section{MATERIALS AND METHODS}

\section{Experimental Design}

The design of this greenhouse study was adapted from a peerreviewed guidance document, that outlines how model system studies should be performed to investigate pathogen die-off in preharvest soils following BSAAO (Harris et al., 2013). Since the primary objective of this study was to characterize population dynamics of different Salmonella strains following soil amendment with poultry litter, each of the study's three independent trials consisted of 24 pots that were irrigated daily (12 with sandyloam soil and 12 with clay loam soil), and inoculated with one of 12 Salmonella strains (i.e., one strain per pot). Since past studies (Holley et al., 2006; Semenov et al., 2009; Underthun et al., 2018; Wang et al., 2018), have shown that irrigation regimen and soil moisture can affect Salmonella survival, three strains were randomly selected and used to inoculate an additional six pots per trial (three with sandy-loam soil and three with clay-loam soil; one strain per pot), for a weekly irrigation regimen (pots irrigated weekly). To account for the impact of amendment (compared to not amending the soil), one strain was randomly selected and used to inoculate an additional two non-amended pots per trial (one with sandyloam soil and one with clay-loam soil). In total, the study consisted of 96 pots [ $(12$ amended pots irrigated daily +3 amended pots irrigated weekly +1 non-amended pot irrigated daily) $\times 2$ soil-types $=32$ pots per trial $\times 3$ independent trials $=96$ total pots], with three replicates for each combination of soil-type, amendment, strain, and irrigation regimen. This number of replicates is consistent with several prior studies (Natvig et al., 2002; Semenov et al., 2009; Schwarz et al., 2014; Fongaro et al., 2017; Hruby et al., 2018; Underthun et al., 2018).

Throughout the study greenhouse conditions were maintained to replicate temperature and humidity during the spring growing season in VA, United States. To ensure that greenhouse conditions remained constant, these parameters were continuously monitored and recorded each time samples were collected (HOBO Micro Station Data Loggers, Onset, Bourne, MA, United States; Supplementary Figure S1).

\section{Inoculum Preparation}

The 12 Salmonella enterica strains used here were selected to represent a diversity of serovars and sources (environmental, clinical, food, animal; Table 1). Strains were pre-adapted to grow in the presence of $50 \mu \mathrm{g} / \mathrm{ml}$ nalidixic acid (NA) to assist in distinguishing the inoculum strains from background microflora, as described by Parnell et al. (2005). Prior to the start of each trial, each NA-adapted strain was cultured from frozen stock $\left(-80^{\circ} \mathrm{C}\right)$ on tryptic soy agar ((TSA) plates (Difco, BD, Sparks, $\mathrm{MD}$, United States) supplemented with $50 \mu \mathrm{g} / \mathrm{ml} \mathrm{NA}$ and incubated at $37^{\circ} \mathrm{C}$ for $24 \mathrm{~h}$. The inoculum was prepared using a modified version of a the protocol described in Sharma et al. (2016). Briefly, three to five colonies per strain were taken from the TAS plates, and inoculated into $200 \mathrm{ml}$ of tryptic soy broth (TSB; Difco, BD) supplemented with $50 \mu \mathrm{g} / \mathrm{ml}$ NA. The broth was then incubated at $37^{\circ} \mathrm{C}$ for $18 \mathrm{~h}$ with agitation $(140 \mathrm{rpm})$.
To achieve a target starting inoculum of $6 \mathrm{log} \mathrm{CFU} / \mathrm{ml}$ for each strain, a $10 \mathrm{ml}$ aliquot of each $18 \mathrm{~h}$ culture was added to separate $990 \mathrm{ml}$ of $0.1 \%$ peptone water (Difco, BD). To confirm the concentration of each inoculum for each strain, serial dilutions in $0.1 \%$ peptone water were plated onto TSA and xylose lysine tergitol (XLT-4) agars (Difco, BD) supplemented with $50 \mu \mathrm{g} / \mathrm{ml} \mathrm{NA}$. Following incubating at $37^{\circ} \mathrm{C}$ for $24 \mathrm{~h}$, colonies on the TSA and XLT- 4 plates were enumerated, and $\log \mathrm{CFU} / \mathrm{ml}$ of Salmonella was calculated.

\section{Soil and Poultry Litter Collection, and Inoculation}

The sandy-loam and clay-loam soil used in the study reported here were obtained from commercial produce fields in Painter, VA, United States and Petersburg, VA, United States, respectively. Soil was collected from the top $20 \mathrm{~cm}$ of the field, sieved to homogenize the soil, and remove rocks, debris, and large aggregates, and air-dried for 7 days. Poultry litter was obtained from a chicken operation in Melfa, VA, United States the morning of each trial. Soil and poultry litter physicochemical properties (e.g., pH, moisture, total carbon, total nitrogen, and phosphorus), were determined by an external lab (Waypoint Analytical; Richmond, VA, United States), and are reported in Supplementary Tables S1 and S2.

Immediately prior to the start of each trial, soil was weighed into $1 \mathrm{~kg}$ portions and added to sterile $1.89 \mathrm{~L}$ plastic pots. Poultry litter was added to soil at a rate of $8.9 \mathrm{Mg} / \mathrm{ha}$ (4 tons per acre) to reflect commercial practices. The amended soil was then inoculated with one of the 12 strains. Briefly, $100 \mathrm{ml}$ of each Salmonella strain inoculum were mixed with $1 \mathrm{~kg}$ of amended soil and sterile distilled water, where it was thoroughly homogenized using a $30 \mathrm{~s}$ shake, $30 \mathrm{~s}$ rub, $30 \mathrm{~s}$ shake procedure, repeated for $5 \mathrm{~min}$. Sterile distilled water was then added to achieve a soil moisture-level of 13 and $23 \%$ for sandy-loam and clay-loam soils, respectively. Pre-study experiments to test the inoculation protocol showed a homogenous distribution of Salmonella in the amended soil following inoculation (Supplementary Table S3; $\sim 4 \quad \log$ CFU/g.). Following homogenization, the inoculated soil was returned to the pot, and each pot transferred to the greenhouse.

In parallel with each trial, six control pots were also run: un-inoculated amended sandy- and clay-loam soil irrigated daily (one per soil-type) and weekly (one per soil-type), and un-inoculated non-amended sandy- and clay-loam soils irrigated daily (one per soil type). Control samples were prepared and handled identically as inoculated soil.

Throughout the study, sterilized distilled water was added to each pot to bring soil moisture to levels that were typically observed in agricultural fields (13\% for sandy-loam and $23 \%$ for clay-loam pots). Water was either added (categorized as an "irrigation event") on a daily or weekly basis to ensure soil moisture was maintained (at $+/-2 \%$ ) using soil moisture probes (TDR150; Spectrum, Aurora, IL, United States). Irrigation regimens (daily or weekly) and soil moisture levels were selected to cover a variety of crops and practices within the Mid-Atlantic and Southeastern regions following the Mid-Atlantic Commercial 


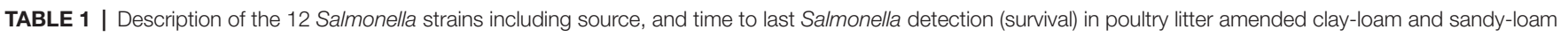
soils by daily and weekly irrigation.

\begin{tabular}{|c|c|c|c|c|c|c|c|}
\hline \multirow{4}{*}{ Strain } & \multirow{4}{*}{ Source } & \multicolumn{6}{|c|}{ Time (day) to last detect (Salmonella survival)a } \\
\hline & & \multicolumn{4}{|c|}{ Poultry litter amended } & \multirow{2}{*}{\multicolumn{2}{|c|}{$\begin{array}{l}\text { Non-amended } \\
\text { Daily irrigation }\end{array}$}} \\
\hline & & \multicolumn{2}{|c|}{ Daily irrigation $^{\mathrm{b}}$} & \multicolumn{2}{|c|}{ Weekly irrigation ${ }^{c}$} & & \\
\hline & & Clay-loam & Sandy-loam & Clay-loam & Sandy-loam & Clay-loam & Sandy-loam \\
\hline S. $4,5,12: i:-$ & $\begin{array}{l}\text { Environmental } \\
\text { (water) }\end{array}$ & 168 & 112 & & & & \\
\hline S. Braenderup & Food (cucumber) & 210 & 112 & 252 & 336 & & \\
\hline S. Enteritidis & $\begin{array}{l}\text { Food (romaine } \\
\text { lettuce) }\end{array}$ & 168 & 112 & & & & \\
\hline S. Javiana & $\begin{array}{l}\text { Environmental } \\
\text { (sediment) }\end{array}$ & 112 & 210 & & & & \\
\hline S. Meleagridis & Animal (cattle) & 84 & 112 & 210 & 252 & & \\
\hline S. Montevideo & $\begin{array}{l}\text { Food (iceberg } \\
\text { lettuce) }\end{array}$ & 210 & 112 & & & & \\
\hline S. Muenchen & $\begin{array}{l}\text { Food (orange } \\
\text { juice) }\end{array}$ & 84 & 84 & & & & \\
\hline S. Newport-F & Food (almond) & 168 & 112 & 336 & 252 & & \\
\hline S. Newport-E & $\begin{array}{l}\text { Environmental } \\
\text { (water) }\end{array}$ & 168 & 112 & & & 56 & 56 \\
\hline S. Paratyphi B & $\begin{array}{l}\text { Environmental } \\
\text { (sediment) }\end{array}$ & 168 & 112 & & & & \\
\hline S. Poona & Clinical (human) & 168 & 112 & & & & \\
\hline S. Saintpaul & Clinical (human) & 168 & 168 & & & & \\
\hline
\end{tabular}

aValues represent the days post-inoculation (dpi) that Salmonella was detectable, including by enrichment of a $25 \mathrm{~g}$ soil sample.

${ }^{b}$ Adjusting for the water loss on a daily basis.

'Adjusting for the water loss on a weekly basis.

Vegetable Production Guide (Wyenandt et al., 2016) and Southeastern US Vegetable Crop Handbook (Kemble et al., 2017).

It is important to note that immediately prior to poultry litter inoculation, the soil and poultry litter were tested for endemic NA-tolerant Salmonella. Soil and poultry litter (25 g sample) were tested for Salmonella before each trial according to protocols described below (Underthun et al., 2018; Food and Drug Administration, 2019).

\section{Sampling and Salmonella Enumeration}

Twenty-five gram composite soil samples were collected from each pot $0,0.167(4 \mathrm{~h}), 1,2,4,7,10,14,21,28,56,84,112$, $168,210,252$, and 336 days post-inoculation, or until Salmonella could no longer be detected after two consecutive sample collections. Following sample collection, Salmonella levels were enumerated. To make the composite soil sample, five $5 \mathrm{~g}$ samples were collected from each pot, and combined with $225 \mathrm{ml}$ of buffered peptone water (BPW; Difco, BD) in a sterile, filtered Whirl-pak bag (Nasco, Modesto, CA, United States). Each bag was hand massaged for 60 s. Standard direct plating method was used until counts neared the limit of detection (LOD; Underthun et al., 2018; Food and Drug Administration, 2019; LOD = $1 \log \mathrm{CFU} / \mathrm{g}$ ). Briefly, $1 \mathrm{ml}$ of each soil sample homogenate (25 g sample and $225 \mathrm{ml} \mathrm{BPW}$ ) was serially diluted in $9 \mathrm{ml}$ of $0.1 \%$ peptone water, and $0.1 \mathrm{ml}$ was plated on XLT-4 supplemented with $50 \mu \mathrm{g} / \mathrm{ml}$ NA (LOD=). Separately, $1 \mathrm{ml}(0.25 \mathrm{ml}$ aliquoted on each of four XLT-4 plates) was plated from the sample bag to reach a LOD of
$1 \log$ CFU/g (Flessa et al., 2005). All XLT-4 plates were incubated at $37^{\circ} \mathrm{C}$ for $24 \mathrm{~h}$.

Once Salmonella counts neared the LOD for the direct plating method, a modified Salmonella most probable number (MPN) method (Gartley et al., 2018; Jay-Russell et al., 2018a,b; Food and Drug Administration, 2019) was used to increase the LOD to $0.25(-0.6 \mathrm{log}) \mathrm{MPN} / \mathrm{g}$. Briefly, $5 \mathrm{ml}$ of the homogenate was transferred into the first column of a 48 well reservoir (eight by six well reservoir; with subsequent columns filled with $4.5 \mathrm{ml}$ of BPW). Each sample was serially diluted (1:10) six times and incubated at $37^{\circ} \mathrm{C}$ for $20 \mathrm{~h}$ shaking $(50 \mathrm{rpm})$. A $50 \mathrm{uL}$ aliquot from each well was then transferred into the corresponding wells of a 48 well reservoir of Rappaport Vassiliadis (RV) broth (Difco, BD; $5 \mathrm{ml}$ of RV in each well). After incubating at $42^{\circ} \mathrm{C}$ for $48 \mathrm{~h}$ shaking $(50 \mathrm{rpm}), 10 \mu \mathrm{l}$ from each well was channel streaked onto XLT-4 supplemented with $50 \mu \mathrm{g} / \mathrm{ml}$ nalidixic acid, and incubated at $37^{\circ} \mathrm{C}$ for up to $48 \mathrm{~h}$. The number of Salmonella positive streaks (out of eight total streaks) was recorded. A presumptive Salmonella positives was indicated by black streaks with a pink/yellow halo. Presumptive Salmonella positives were re-streaked onto TSA plates, incubated at $37^{\circ} \mathrm{C}$ for $24 \mathrm{~h}$. Up to four colonies per streak were confirmed as Salmonella by PCR amplification of the invA gene (McEgan et al., 2013; Strawn et al., 2013a). PCR-confirmed streaks were counted, and MPN values calculated as previously described (http://standards.iso.org/iso/7218/). The remainder of the sample homogenate was enriched concomitantly with the MPN 
enumeration using standard FDA BAM methods (Food and Drug Administration, 2019; LOD = 1 cell/25 g).

\section{Statistical Analysis}

All analyses were performed in $\mathrm{R}$ version 3.3 .1 or 3.3.5 (R Foundation for Statistical Computing, Vienna, Austria). For all analyses, the data were divided into three subsets: (i) amended pots irrigated daily ("the daily dataset"; $N=72$ ), (ii) amended pots that were inoculated with S. Braenderup, S. Newport-F, or $S$. Meleagridis, since these were the three strains that received both daily and weekly irrigation ("the irrigation dataset"; $N=18$ ), and (iii) pots that were inoculated with $S$. Newport-E, since this was the only strain that was inoculated into both amended and non-amended pots ("the amendment dataset"; $N=6$ ).

\section{Effect of Soil-Type, Irrigation, and Amendment on Salmonella Survival and Die-off}

The daily dataset was used to quantify the impact of soil-type on die-off rate, while controlling for strain. The irrigation dataset was used to quantify the impact of irrigation regimen on die-off rate, while controlling for strain and the amendment dataset was used to quantify the impact of amendment on die-off rate, while controlling for strain. It is important to note that the small size of the irrigation and amendment datasets is a major limitation of this study; however, these analyses were included in the study reported here for comparison to prior literature (Holley et al., 2006; You et al., 2006; Semenov et al., 2009; Sharma et al., 2016; Underthun et al., 2018; Wang et al., 2018; Shah et al., 2019), while investigating strain differences. To perform these analyses, two sets of general linear models were developed. The outcome of the models were either (i) time to last detection of Salmonella (i.e., the last time point where Salmonella could be isolated from a sample, including $25 \mathrm{~g}$ enrichments), which was used to examine the effect of each soil-type, strain, irrigation regimen, and soil amendment on Salmonella survival and (ii) concentration of Salmonella at each time point (log CFU or MPN/g). Depending on the dataset, a fixed effect of irrigation regimen (weekly or daily; irrigation dataset) or amendment (poultry litter-amended or non-amended; amendment dataset) was also included. In models where the outcome was Salmonella concentration, time since inoculation was also included as a fixed effect. The effect for time was interpreted as the average daily die-off rate (i.e., average change in log CFU or MPN/g per day). All general linear mixed models included soil-type (sandy- or clay-loam) and trial $(1,2$, or 3$)$ as fixed effects, and strain as a random effect.

\section{Effect of Strain on Salmonella Survival and Die-off} The daily dataset was used to compare the die-off rate for each of the 12 strains in poultry litter amended soils. Using the LmList function in the lme4 $\mathrm{R}$ package separate linear models were built for each Salmonella strain. The outcome was Salmonella concentration, and the fixed effects were time since inoculation, trial, and soil-type. Die-off rates between strains were compared visually using the $95 \%$ confidence intervals (CI) for die-off rate (i.e., the effect estimate for time since inoculation). If the $95 \% \mathrm{CI}$ did not overlap, it was concluded that the die-off rates between the two strains were significantly different. A limitation to these analyses is the small number of pots inoculated with each strain; however, prior studies have used similar study units (Natvig et al., 2002; Semenov et al., 2009; Schwarz et al., 2014; Fongaro et al., 2017; Hruby et al., 2018; Underthun et al., 2018).

\section{Effect of Interactions Between Soil-Type, Strain Irrigation, and Amendment on Salmonella Survival} To identify specific combinations of soil-type, irrigation regimen, soil amendment, and strain associated with decreased or increased Salmonella survival, a conditional inference tree (cTree) was built using the full dataset and the partykit package. Since the smallest number of pots included in a given treatment were 3 , the minbucket parameter was set to 6 to prevent overfitting; the mincriterion parameter was also set to 0.95 to prevent overfitting. Separate trees were also built using the same parameters, but using the individual datasets (as opposed to the full dataset), to see if there were additional interactions, not evident when the full dataset was used.

\section{RESULTS AND DISCUSSION}

The study reported here characterized strain variability and the influences of soil-type, irrigation regimen, and amendment on the concentration of Salmonella. The regression tree analysis showed that strain, soil-type, irrigation regimen, and amendment all significantly influenced the survival of Salmonella in agricultural soils (Figure 1). The findings of the regression tree analysis are supported by the results of the general linear mixed models, which also showed that soil-type, irrigation regimen, and amendment significantly impacted Salmonella survival time (Table 2); as well as, die-off rate (Table 3; $p \leq 0.05)$. To our knowledge, this is the first study to quantify the variability for 12 Salmonella strains in poultry litter amended soils under different conditions (i.e., soil-types) and management practices (i.e., irrigation regimens). In fact, nearly 40 years ago, Zibilske and Weaver (1978) described a critique of their Salmonella survival in soil study that only a single strain was used, as such the study reported here is long overdue. There are some limitations to the study reported here, such as the sample size, and the fact that this was a greenhouse study that cannot precisely replicate field conditions. As such, additional studies with a larger number of samples are needed to determine if these findings are reproducible; as well as test other factors such as, different soil-types (e.g., true sand and loam), irrigation practices (e.g., flood and dry-land production), and soil amendments (e.g., bovine and horse). Despite these limitations, this study is consistent with past research (using single strains, or cocktail; You et al., 2006; Semenov et al., 2009; Andino and Hanning, 2015; Underthun et al., 2018; Harrand et al., 2019; Shah et al., 2019), and also shows the variability of Salmonella strains under different agricultural parameters. Data and findings generated here can be used in (i) future risk 


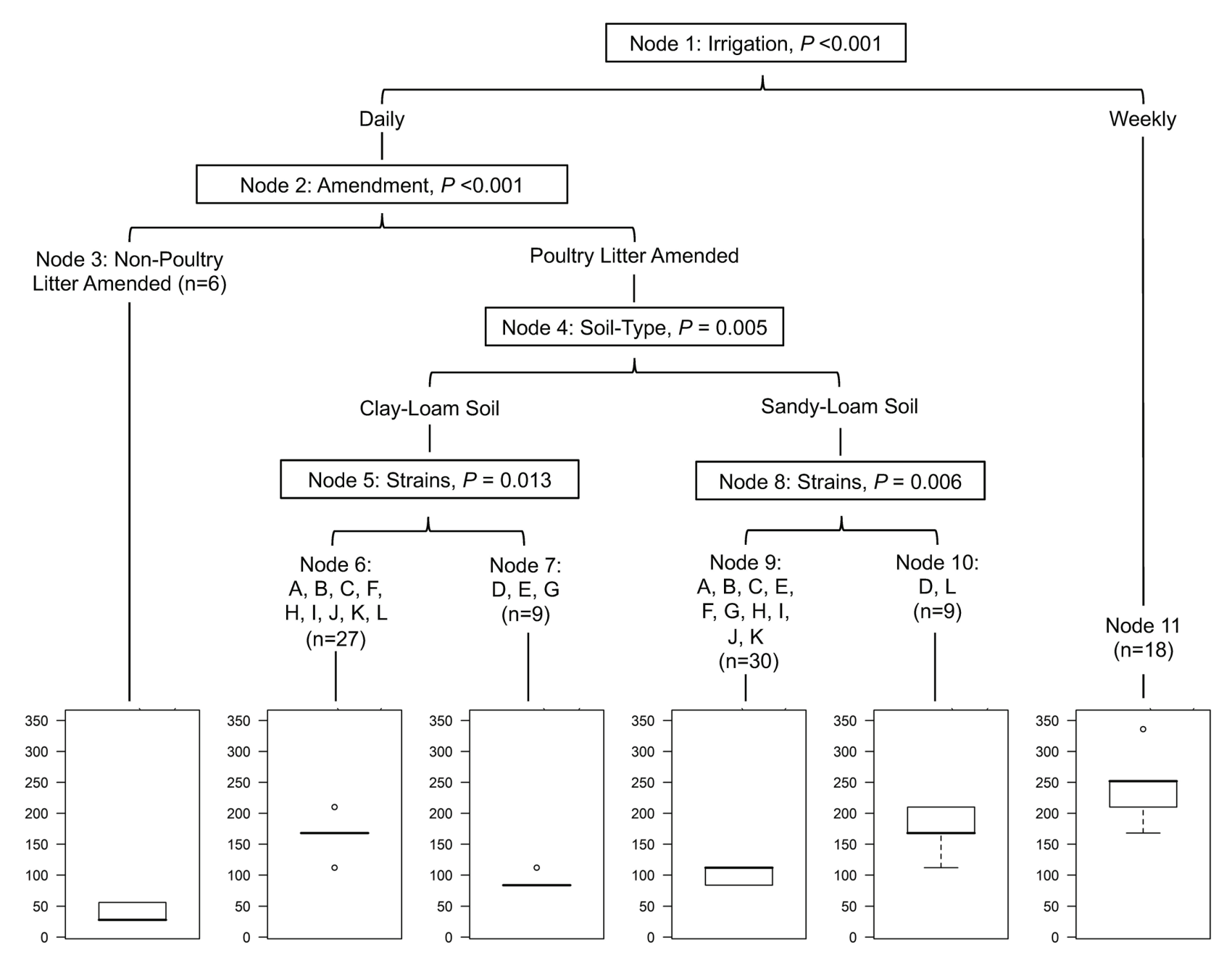

FIGURE 1 | Conditional inference tree (cTree) built showing potential interactions in the full dataset between irrigation regimen, soil amendment, soil-type, and strain, and their impact on the total length of time Salmonella remained detectable in the study reported here. For example, Salmonella survives the longest in pots receiving weekly irrigation, and the shortest in pots receiving no soil amendment. However, for amended pots receiving daily irrigation, survival time was dependent on soil-type and strain. Bar plots show the expected survival of Salmonella (d) in each terminal node. Letters represent the following Salmonella strains:

A (S. 4,5,12:i:-), B (S. Braenderup), C (S. Enteritidis), D (S. Javiana), E (S. Meleagridis), F (S. Montevideo), G (S. Muenchen), H (S. Newport-F), I (S. Newport-E), J (S. Paratyphi B), K (S. Poona), and L (S. Saintpaul).

assessments, (ii) selection of strains for future challenge and validation studies, especially when used together with whole genome sequencing data that may characterize the molecular determinants for environmental adaptation and survival (e.g., worst case contamination scenarios), and (iii) identification of best practices for application of BSAAO, like poultry litter, to agricultural fields.

\section{Survival and Die-off Rates in Amended Soils Receiving Daily Irrigation Were Significantly Associated With Salmonella Strain}

Across the study, the total time that Salmonella survived ranged between 84 and 210 days (mean = 144 days; Figure 2). In poultry litter amended sandy-loam soil pots, the concentration of all strains, except $S$. Poona, increased between inoculation and 7 days post-inoculation (dpi), and remained elevated until $14 \mathrm{dpi}$ (Supplementary Table S4). On average, Salmonella concentrations started to decrease 14 dpi (Supplementary Table S4). Conversely, in amended clay-loam soil, all strains observed a 0.5-1.5 log $\mathrm{CFU}$ or $\mathrm{MPN} / \mathrm{g}$ reduction $4 \mathrm{~h} \mathrm{dpi}$; for some of the strains, subsequent growth occurred with an increase between inoculation and 4-7 dpi (Supplementary Table S5). While S. Saintpaul was the only strain to sort into the node for longer survival (average 168 days) in both sandy- and clay-loam amended soils, $S$. Javiana, and S. 4,5,12:i:-, S. Braenderup, S. Enteritidis, S. Montevideo, S. Newport-F, S. Newport-E, S. Paratyphi B, and S. Poona (cTree) were sorted in to the longer survival nodes for sandy- and clayloam soils, respectively (Figure 1). This suggests that the effect of 
TABLE 2 | Results of general mixed models that were developed to investigate the impact of soil-type, irrigation regimen, and soil amendment on Salmonella survival (i.e., total days Salmonella was at detectable levels for each pot in this study).

\begin{tabular}{|c|c|c|c|c|}
\hline Data set $\left(\mathbf{R}^{2}\right)$ & Factor & Effect estimate & $95 \% \mathrm{Cl}$ & $p$-value \\
\hline \multirow[t]{4}{*}{ Soil-type $(0.35)^{\mathrm{a}}$} & Trial $(\text { one }=\text { reference })^{b}$ & & & 0.188 \\
\hline & Two & -29.56 & $-19.53,17.20$ & 0.902 \\
\hline & Three & -15.75 & $-34.11,2.61$ & 0.101 \\
\hline & Sandy soil (clay = reference) ${ }^{d}$ & -29.56 & $-44.55,-14.56$ & $<0.001$ \\
\hline \multirow[t]{6}{*}{ Irrigation $(0.73)^{\mathrm{c}}$} & Trial $(\text { one }=\text { reference })^{b}$ & & & 0.580 \\
\hline & Two & -12.83 & $-45.37,19.71$ & 0.462 \\
\hline & Three & -17.50 & $-50.04,15.04$ & 0.317 \\
\hline & Sandy soil (clay = reference) ${ }^{d}$ & -10.89 & $-37.46,15.68$ & 0.444 \\
\hline & Weekly irrigation regimen & & & \\
\hline & $(\text { daily }=\text { Reference })^{e}$ & $127.56^{\ominus}$ & 101.00, 154.12 & $<0.001$ \\
\hline \multirow[t]{6}{*}{ Amendment $(0.86)^{\dagger}$} & Trial $(\text { one }=\text { reference })^{b}$ & & & 0.109 \\
\hline & Two & 14.00 & $-19.50,47.50$ & \\
\hline & Three & -21.00 & $-54.50,12.50$ & \\
\hline & Sandy soil (clay $=$ reference) ${ }^{d}$ & -23.33 & $-50.68,4.02$ & 0.083 \\
\hline & Poultry litter amendment (no & & & \\
\hline & amendment = reference) & $88.67^{g}$ & $61.32,116.02$ & $<0.001$ \\
\hline
\end{tabular}

${ }^{a} 17 \%$ of variance in Salmonella survival is explained by the fixed effects shown here, and $18 \%$ of variance in Salmonella survival is explained by the random effect of strain.

${ }^{b}$ The estimated change in time to last detect when the samples were collected as part of trials two or three compared to trail one.

${ }^{\circ} 65 \%$ of variance in Salmonella survival is explained by the fixed effects shown here, and $8 \%$ of variance in Salmonella survival is explained by the random effect of strain.

${ }^{d}$ The estimated change in time (days) to last detect when the soil was sandy-loam compared to clay-loam (which was the reference-level). For example, this means that Salmonella is expected to survive 30 days longer in clay soil than sandy soil based on the soil-type model.

eSalmonella was predicted to survive 128 days longer when weekly compared to daily irrigation was performed.

${ }^{f} 86 \%$ of variance in Salmonella survival is explained by the fixed effects shown here since there were no random effects used in the amendment model.

'Salmonella was predicted to survive 89 days longer in poultry litter amended pots compared to non-amended pots.

soil-type, and other factors, on survival may be strain-specific; however, investigating potential interactions between strain, soiltype, and the other factors included here were outside the scope of the study and should be investigated as part of future research projects.

In the general linear models, strain accounted for up to $18 \%$ of variance in survival and $9 \%$ of variance in die-off rate, suggesting variation between strains (Tables 2 and 3). Separately from the general linear models' individual log-linear models were developed to compare die-off rates (i.e., the effect estimate for time) between Salmonella strains (Table 4). By comparing the $95 \%$ CI for the die-off rates, we could identify significant differences between strains. For example, S. Muenchen had a faster daily die-off rate $(-0.060 \mathrm{log} \mathrm{CFU}$ or $\mathrm{MPN} / \mathrm{g}$ per day; standard error $=0.005)$, compared to all 12 strains. Conversely, S. Braenderup, S. Meleagridis, and S. Newport-F had significantly slower daily die-off rates, compared to the other nine strains (Table 4). S. Javiana and S. Montevideo had slower die-off rates, than $S$. Muenchen, but had faster die-off rates than $S$. Braenderup, S. Meleagridis, and $S$. Newport-F (Table 4). Interestingly, there was a significant effect of soiltype for nine of the 12 strains, with Salmonella concentrations being higher in sandy-loam soils, compared to clay-loam soils (Table 4). This supports the conclusion described above that the effect of environmental factors, such as soil-type, on Salmonella survival and die-off is strain-specific; however, it may also be a function of the small sample size here.

This study examined the variation in the survival and die-off of a large number of Salmonella strains $(n=12)$ in amended sandy- and clay-loam soils. The comparison of individual (single) strains (not in cocktails) is important, as recent papers (Andino and Hanning, 2015; Harrand et al., 2019) have shown that different Salmonella strains can vary substantially in their responses to environmental stresses (e.g., temperature and moisture), which may impact survival. Multiple studies have investigated the survival of a single strain (e.g., You et al., 2006; Semenov et al., 2009; Shah et al., 2019) or a strain cocktail (e.g., Underthun et al., 2018) in amended and non-amended soils. For example, You et al. (2006) reported the die-off rate for $S$. Newport in soil amended with bovine manure similar to those reported here (ranged from -0.03 to $-0.04 \log \mathrm{CFU} / \mathrm{g}$ per day). That being said, the current study does not observe the interactions between different Salmonella strains and its influence on the survival in soil and poultry litter amended soil. Further studies may look to investigate the interactions of different Salmonella strains in combination.

\section{Salmonella Survival and Die-off Rates Were Significantly Different in Poultry Litter Amended Soils That Received Weekly Irrigation, Compared to Daily Irrigation}

Three strains (S. Braenderup, S. Newport-F, and S. Meleagridis) were exposed to two different irrigation regimens (daily and weekly). Salmonella survived on average 128 days longer (95\% CI $101.00,154.12)$ when irrigated weekly compared to daily according to the general linear model (Table 2). While, 
TABLE 3 | Results of log-linear general mixed models that were developed to investigate the impact of soil-type, irrigation regimen, and soil amendment on Salmonella daily die-off rate.

\begin{tabular}{|c|c|c|c|c|}
\hline Data set $\left(\mathbf{R}^{2}\right)$ & Factor & Effect estimate & $95 \% \mathrm{Cl}$ & $P$-value \\
\hline \multirow[t]{5}{*}{ Soil-type $(0.70)^{a}$} & Daily die-off rate ${ }^{b}$ & -0.03 & $-0.03,-0.03$ & $<0.001$ \\
\hline & Trial (one =reference) ${ }^{c}$ & & & 0.004 \\
\hline & Two & -0.19 & $-0.34,-0.04$ & 0.015 \\
\hline & Three & -0.25 & $-0.40,-0.10$ & 0.001 \\
\hline & Sandy soil (clay = reference) $)^{e}$ & 0.66 & $0.54,0.79$ & $<0.001$ \\
\hline \multirow[t]{7}{*}{ Irrigation $(0.71)^{\mathrm{d}}$} & Daily die-off rate ${ }^{b}$ & -0.02 & $-0.02,-0.02$ & $<0.001$ \\
\hline & Trial $(\text { one }=\text { reference })^{c}$ & & & 0.034 \\
\hline & Two & -0.24 & $-0.48,0.00$ & 0.051 \\
\hline & Three & -0.30 & $-0.55,-0.06$ & 0.014 \\
\hline & Sandy soil (clay = reference) ${ }^{e}$ & 0.43 & $0.24,0.63$ & $<0.001$ \\
\hline & Irrigation regimen & & & \\
\hline & $(\text { daily }=\text { reference })^{f}$ & -0.03 & $-0.23,0.18$ & 0.808 \\
\hline \multirow[t]{7}{*}{ Amendment $(0.77)^{g}$} & Daily die-off rate ${ }^{b}$ & -0.05 & $-0.05,-0.04$ & $<0.001$ \\
\hline & Trial $(\text { one }=\text { reference })^{c}$ & & & 0.468 \\
\hline & Two & -0.19 & $-0.58,0.21$ & 0.356 \\
\hline & Three & -0.20 & $-0.60,0.20$ & 0.331 \\
\hline & Sandy soil (clay $=$ reference) $)^{e}$ & 0.82 & $0.50,1.15$ & $<0.001$ \\
\hline & Poultry litter amendment (no & & & \\
\hline & amendment $=$ reference $)^{\mathrm{h}}$ & 2.60 & $2.25,2.94$ & $<0.001$ \\
\hline
\end{tabular}

${ }^{a} 61 \%$ of variance in Salmonella die-off is explained by the fixed effects shown here, and $9 \%$ of variance in Salmonella die-off is explained by the random effect of strain.

${ }^{b}$ The die-off rate represents the daily decrease in $\log _{10}$ Salmonella concentration when all other variables in the model were held constant.

${ }^{c}$ The estimated difference in $\log _{10}$ Salmonella concentration when the samples were collected as part of trials two or three compared to trail one.

${ }^{d} 52 \%$ of variance in Salmonella die-off is explained by the fixed effects shown here, and $19 \%$ of variance in Salmonella die-off is explained by the random effect of strain.

eThe estimated difference in $\log _{10}$ Salmonella concentration when the soil was sandy-loam compared to clay-loam (which was the reference-level). For example, this means that the $\log _{10}$ Salmonella concentration is expected to be $0.66 \log _{10}$ most probable number (MPN) or CFU higher in sandy-loam soil than clay-loam soil based on the soil-type model.

The $\log _{10}$ Salmonella concentration is expected to be $0.03 \log _{10}$ MPN or CFU lower when irrigation was performed weekly as opposed to daily.

${ }^{977 \%}$ of variance in Salmonella survival is explained by the fixed effects shown here since there were no random effects used in the amendment model.

${ }^{n}$ The $\log _{10}$ Salmonella concentration is expected to be $2.60 \log _{10}$ MPN or CFU higher when the soil was amended compared to non-amended.

Salmonella concentration was, on average, higher in poultry litter amended soils that received daily irrigation, compared to weekly irrigation (Figure 3), this difference was not significant with regard to die-off rate (Table 3 ). The magnitude of the effect of irrigation regimen on survival and die-off was almost 10-times that of soil type (Tables 2 and 3 ). Given our finding that die-off rates varied significantly between strains, and total survival time appeared to be dependent on both strain and soil-type in the regression tree, future studies should test if the effect of irrigation regimens substantially influence other Salmonella strain's survival. Additionally, irrigation regimen may also interact with other soil characteristics (e.g., soil particle size and slope) to influence Salmonella survival (Sharma and Reynnells, 2018); thus, future studies should investigate the effect of such interactions.

\section{Salmonella Survived Significantly Longer in Poultry Litter Amended Soils Compared to Non-amended Soils}

Amendment with poultry litter significantly prolonged Salmonella Newport-E survival by 89 days $(95 \% \mathrm{CI}=61.32,116.02$, $p \leq$ 0.001; Table 2; Figure 4). Overall, these findings are consistent with previous studies (Baloda et al., 2001; Islam et al., 2004a; Holley et al., 2006; You et al., 2006; Nyberg et al., 2010; Ongeng et al., 2011; Hruby et al., 2018; Shah et al., 2019) that reported Salmonella survival increased in soils amended with BSAAO (e.g., poultry litter and bovine manures). For example, You et al. (2006) found that addition of bovine manure to agricultural soils increased $S$. Newport concentrations by as much as $400 \%$ within the first 3 days. Baloda et al. (2001) observed that Salmonella survive up to 299 days in hog slurry amended agricultural soils, while Hruby et al. (2018) detected Salmonella in soil samples from poultry litter amended plots nearly a full year after application. Additionally, the die-off rate of $S$. Newport-E was slower in poultry litter amended soils, compared to non-amended soils (Table 4). In fact, application of poultry litter amendment increased the concentration of Salmonella by $2.6 \log \mathrm{CFU} / \mathrm{g}$ $(95 \% \mathrm{CI}=2.3,2.9 ; p<0.001)$, which was the largest effect observed for any of the factors (e.g., soil-type, irrigation regimen, and amendment) investigated in the study reported here (Table 3). The study reported here confirms that application of BSAAO to soils (e.g., poultry litter) facilitates Salmonella survival. The 120/90 days application interval outlined by the USDA National Organic Program (USDA, 2015, 2020) for growers who use raw manures in produce production is supported by most of the Salmonella strains examined in this study, in that Salmonella was last detected in a time period shorter than 120 days for 10 of 12 strains in poultry litter amended sandy-loam and for three out of 12 strains in poultry litter amended clay-loam amended soils that received daily irrigation. However, there were certain strains that survived $>120$ dpi 


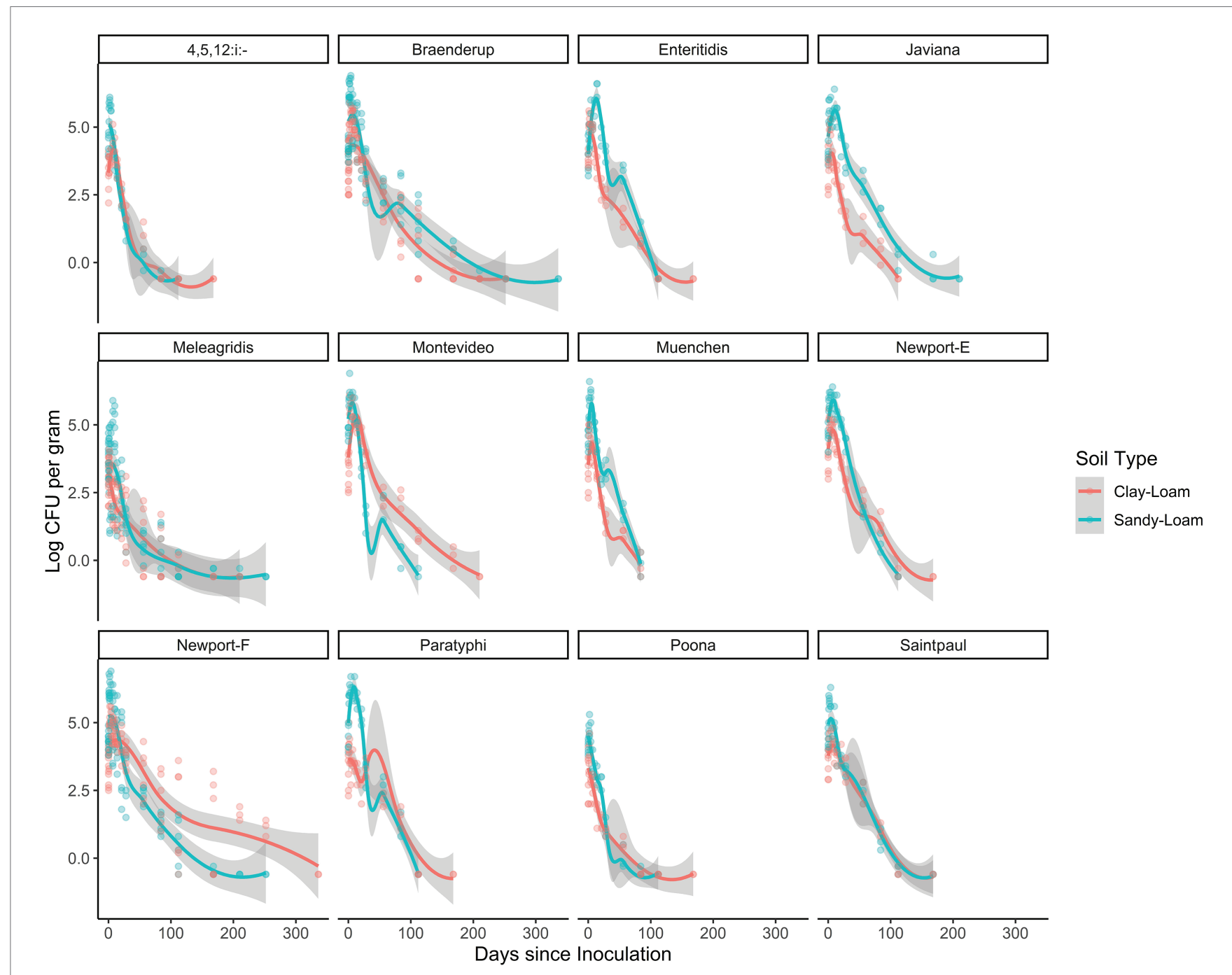

FIGURE 2 | Loess-smoothed regressions showing concentration and 95\% confidence intervals (gray shading) for each strain in poultry litter-amended clay-loam (red line) and sandy-loam (teal line) soils.

under daily and weekly irrigation regimens; in fact, $S$. Braenderup and $S$. Newport-F survived up to $336 \mathrm{dpi}$ in sandy-loam and clay-loam soil, under a weekly irrigation regimen. This finding suggests that, depending on the target risk reduction or risk associated with consumption of produce grown in amended soil, the USDA National Organic Program may be sufficient for managing food safety risks associated with BSAAO use under certain conditions, but not all conditions. As such, research into condition-specific modifiers may be needed to better manage these risks due to BSAAO application.

\section{Salmonella Strain Die-off Rates Were Significantly Associated With Soil-Type in Poultry Litter Amended and Non-amended Soils Under Both Irrigation Regimens}

Six general log-linear models were developed to quantify the effect of soil-type on Salmonella survival ( $N=3$ models) and die-off ( $N=3$ models) in (i) amended pots receiving daily irrigation, (ii) amended pots receiving daily vs. weekly irrigation, and (iii) amended vs. non-amended pots receiving daily irrigation (Tables 2 and 3). According to all three die-off models, soiltype was significantly associated with Salmonella die-off $(p<0.001)$. In fact, the models for amended pots receiving daily irrigation fixed effects accounted for 17 and $61 \%$ of variance in survival and die-off rate, respectively; since the only fixed effects were trial and soil-type, and only soil-type was significant, we can conclude that the majority of the variance was accounted for by soil-type. However, soil-type was only associated with survival in the soil type dataset; this may have been a product of the small number of samples available for use in the irrigation $(N=18)$ and amendment $(N=6)$ datasets. Based on the general linear models, Salmonella die-off was slower in clay-loam soils for some of the strains, such as Montevideo and Newport F, compared to sandy-loam soils, which is consistent with past findings. For example, Jechalke et al. (2019) found that Salmonella die-off rates were 


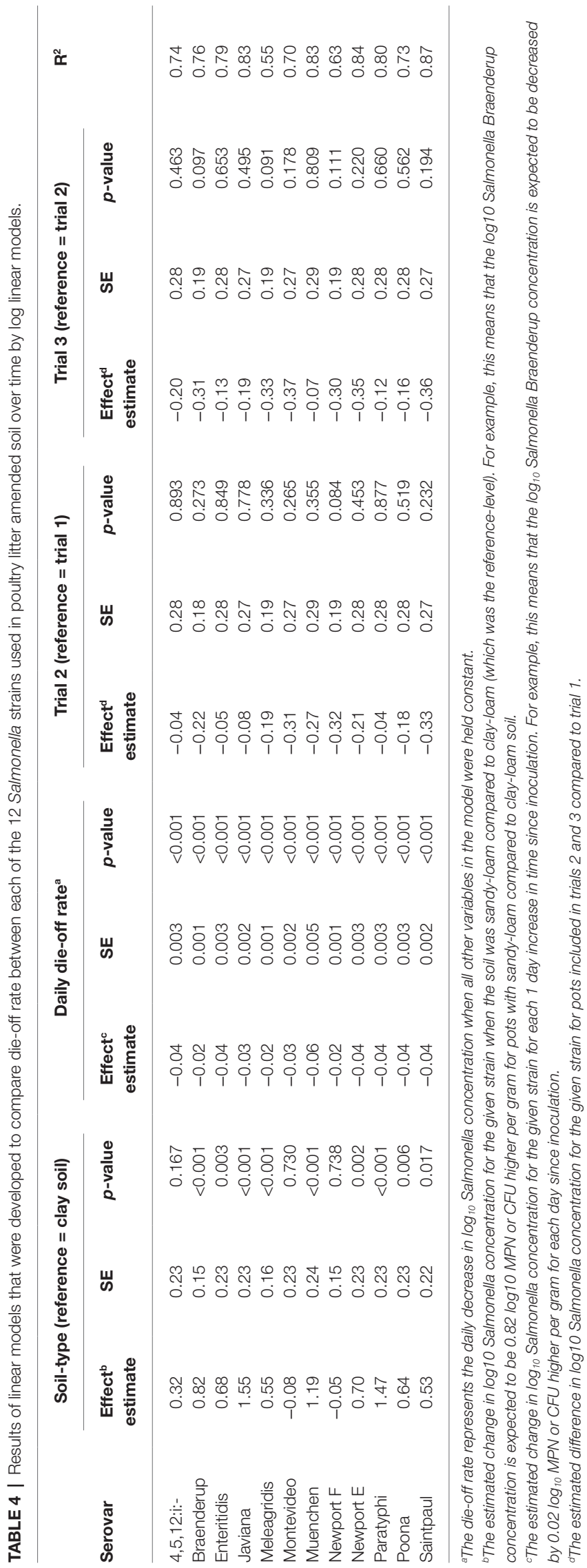

significantly higher in the sand $(-0.076 \pm 0.014 \log$ CFU/day), compared to loam $(-0.034 \pm 0.015 \log \mathrm{CFU} /$ day $)$. Other studies (Platz, 1980; Bech et al., 2010; Fongaro et al., 2017; Underthun et al., 2018) have demonstrated that soil-type impacts Salmonella persistence; in addition to other factors, such as temperature and moisture. For example, one study (Platz, 1980) observed higher isolation rates of Salmonella in loam-type and clay-type soils, compared to sandy-type soils. Sandy-type soils typically drain faster with more flow; and thereby, filter microorganisms at a more frequent pace (less-absorptive), compared to loamand clay-type soils. However, another study (Fongaro et al., 2017) found Salmonella survival was significantly lower in clay soil, than in sandy soil. The authors of the study hypothesized clay soils may have more alkaline $\mathrm{pH}$, higher organic matter, and higher nutrient contents (due to reduced leaching and better water retention), which may have influenced survival. Thus, the data reported here, and by others, suggests that soil-type can influence Salmonella die-off, and in some cases, Salmonella survival. These results suggest future studies should investigate additional soil-types (i.e., different mixtures of sand, loam, and clay) to determine Salmonella survival under different field conditions.

\section{CONCLUSION}

Findings from this study suggest a one-size fits all standard for application of BSAAO to agricultural fields would be challenging as there is significant variability in Salmonella survival and die-off by strain; as well as variability by environmental and management factors. Moreover, these findings suggest possible worst-case contamination scenarios that can be used to implement robust recommendations and potential policy decisions. Future studies should critically evaluate strains, soil-type, and management practices to validate potential interventions, guidance, and policy decisions. Based on the results of the study reported here, there are several candidate Salmonella strains to use in challenge and validation studies as worst-case contamination scenarios. Prior literature (Harris et al., 2013; Andino and Hanning, 2015; Harrand et al., 2019; Ramos et al., 2019) has described the importance of using worst-case contamination scenarios (i.e., conservative approach) and a diverse set of strains, as survival and behavior can vary considerably by factor (e.g., soil-type). For example, S. Saintpaul survived 168 days in sandy- and clay-loam amended soils exposed to daily irrigation, and according to the cTree model had one of the longest times to detect Salmonella.

Additionally, $S$. Braenderup, $S$. Meleagridis, and $S$. Newport-F each had significantly slower die-off rates, compared to the other nine strains, with $S$. Newport-F being the slowest of those three influenced by soil-type according to models. Additionally, the use of geographically relevant strains should also be considered to assess persistence and quantify risk of long-term soil contamination, as other studies (Gorski et al., 2011; Strawn et al., 2014; Bell et al., 2015; Jokinen et al., 2015) have demonstrated different Salmonella strains can be geographically distributed in specific produce growing regions. For example, S. Newport-E (used in the study reported here) is geographically relevant to 


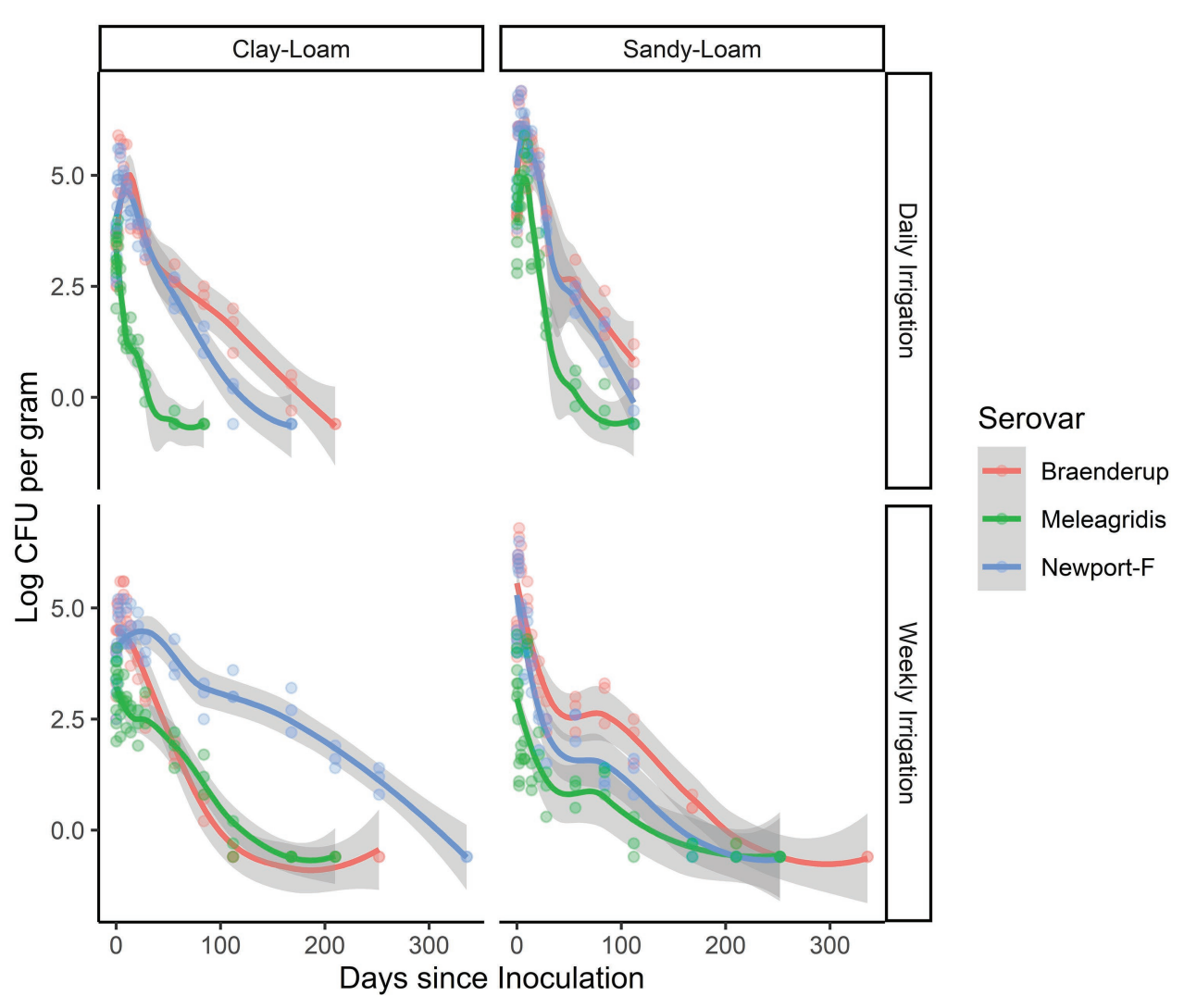

FIGURE 3 | Less-smoothed regressions showing concentration and 95\% confidence interval (gray shading) for each strain S. Braenderup (red line), S. Meleagridis (green line), and S. Newport-F (blue line) in poultry litter-amended clay and sandy soils.

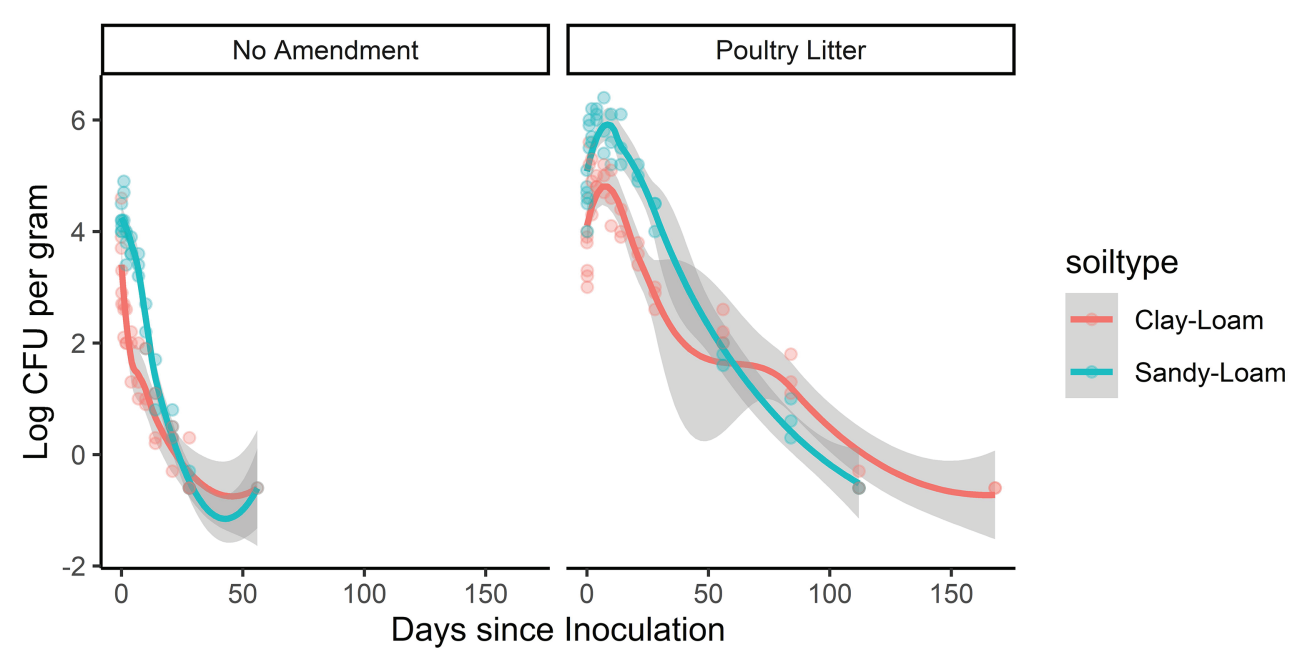

FIGURE 4 | Loess-smoothed regressions showing concentration and 95\% confidence intervals (gray shading) for S. Newport-E in poultry litter-amended clay-loam (red line) and sandy-loam (teal line) soils.

the Eastern Shore of Virginia, which has sandy-loam soil (also used in this study), and has been associated with tomato-borne outbreaks (Greene et al., 2008; Bell et al., 2015). Overall, Salmonella survival and die-off is affected by soil characteristics (e.g., soil-type) and management practices (e.g., irrigation regimen and amendment), and the effect of these factors may 
be strain-specific. Thus, data can assist in risk assessment and strain selection for use in challenge and validation studies.

\section{DATA AVAILABILITY STATEMENT}

The raw data supporting the conclusions of this article will be made available by the corresponding author.

\section{AUTHOR CONTRIBUTIONS}

LS, DO, YC, and DI contributed to the study conception and design. LS, SR, and CB contributed to the acquisition of the data. LS, DW, and CB contributed to the analysis and interpretation of the data and drafting of the manuscript. LS, DW, CB, SR, $\mathrm{DO}, \mathrm{YC}$, and DI contributed to the critical revisions of the manuscript. All authors contributed to the article and approved the submitted version.

\section{FUNDING}

This project was funded, in part, by the Food and Drug Administration (FDA), and by the Specialty Crop Block Grant Program at the United States Department of Agriculture

\section{REFERENCES}

Alali, W. Q., Thakur, S., Berghaus, R. D., Martin, M. P., and Gebreyes, W. A. (2010). Prevalence and distribution of Salmonella in organic and conventional broiler poultry farms. Foodborne Pathog. Dis. 7, 1363-1371. doi: 10.1089/ fpd.2010.0566

Andino, A., and Hanning, I. (2015). Salmonella enterica: survival, colonization, and virulence differences among Serovars. Sci. World J. 2015:e520179. doi: $10.1155 / 2015 / 520179$

Baloda, S. B., Christensen, L., and Trajcevska, S. (2001). Persistence of a Salmonella enterica Serovar Typhimurium DT12 clone in a piggery and in agricultural soil amended with Salmonella-contaminated slurry. Appl. Environ. Microbiol. 67, 2859-2862. doi: 10.1128/AEM.67.6.2859-2862.2001

Bech, T. B., Johnsen, K., Dalsgaard, A., Laegdsmand, M., Jacobsen, O. H., and Jacobsen, C. S. (2010). Transport and distribution of Salmonella enterica serovar Typhimurium in loamy and sandy soil monoliths with applied liquid manure. Appl. Environ. Microbiol. 76, 710-714. doi: 10.1128/AEM.00615-09

Bell, R. L., Zheng, J., Burrows, E., Allard, S., Wang, C. Y., Keys, C. E., et al. (2015). Ecological prevalence, genetic diversity, and epidemiological aspects of Salmonella isolated from tomato agricultural regions of the Virginia eastern shore. Front. Microbiol. 6:415. doi: 10.3389/fmicb.2015.00415

Callejón, R. M., Rodríguez-Naranjo, M. I., Ubeda, C., Hornedo-Ortega, R., Garcia-Parrilla, M. C., and Troncoso, A. M. (2015). Reported foodborne outbreaks due to fresh produce in the United States and European Union: trends and causes. Foodborne Pathog. Dis. 12, 32-38. doi: 10.1089/fpd.2014.1821

CDC (2016). Outbreak of Salmonella Newport infections linked to cucumbers United States, 2014. Available at: https:/www.cdc.gov/mmwr/preview/mmwrhtml/ mm6406a3.htm?s_cid=mm6406a3_e (Accessed July 16, 2018).

Chandler, D. S., and Craven, J. A. (1980). Relationship of soil moisture to survival of Escherichia coli and Salmonella typhimurium in soils. Aust. J. Agric. Res. 31, 547-555. doi: 10.1071/AR9800547

Chinivasagam, H. N., Redding, M., Runge, G., and Blackall, P. J. (2010). Presence and incidence of food-borne pathogens in Australian chicken litter. Br. Poult. Sci. 51, 311-318. doi: 10.1080/00071668.2010.499424
(USDA) through the Virginia Department of Agriculture and Consumer Services (VDACS). Funding for this work was also provided by the Virginia Agricultural Experiment Station and the Hatch Program of the National Institute of Food and Agriculture, USDA. Manuscript preparation and data analyses were supported by the National Institute of Environmental Health Sciences of the National Institutes of Health (NIH) under award number T32ES007271. Its contents are solely the responsibility of the authors and do not necessarily represent the official views of the FDA, USDA, $\mathrm{NIH}$, and VDACS.

\section{ACKNOWLEDGMENTS}

We are grateful for the laboratory assistance of Laura Truitt, Rachel Pfuntner, Amy Harrison, and Jill Pollok. We also thank Steven Duret for assistance with study design and Jane Van Doren for thoughtful discussions on data interpretation.

\section{SUPPLEMENTARY MATERIAL}

The Supplementary Material for this article can be found online at: https://www.frontiersin.org/articles/10.3389/fmicb.2021.590303/ full\#supplementary-material

Cooley, M. B., Quiñones, B., Oryang, D., Mandrell, R. E., and Gorski, L. (2014). Prevalence of Shiga toxin producing Escherichia coli, Salmonella enterica, and Listeria monocytogenes at public access watershed sites in a California central coast agricultural region. Front. Cell. Infect. Microbiol. 4:30. doi: 10.3389/fcimb.2014.00030

Danyluk, M. D., Nozawa-Inoue, M., Hristova, K. R., Scow, K. M., Lampinen, B., and Harris, L. J. (2007). Survival and growth of Salmonella Enteritidis PT 30 in almond orchard soils. J. Appl. Microbiol. 104, 1391-1399. doi: 10.1111/j. 1365-2672.2007.03662.x

Donado-Godoy, P., Gardner, I., Byrne, B. A., Leon, M., Perez-Gutierrez, E., Ovalle, M. V., et al. (2012). Prevalence, risk factors, and antimicrobial resistance profiles of Salmonella from commercial broiler farms in two important poultry-producing regions of Colombia. J. Food Prot. 75, 874-883. doi: 10.4315/0362-028X.JFP-11-458

Elgroud, R., Zerdoumi, F., Benazzouz, M., Bouzitouna-Bentchouala, C., Granier, S. A., Fremy, S., et al. (2009). Characteristics of Salmonella contamination of broilers and slaughterhouses in the region of Constantine (Algeria). Zoonoses Public Health 56, 84-93. doi: 10.1111/j.1863-2378.2008.01164.x

Flessa, S., Lusk, D. M., and Harris, L. J. (2005). Survival of Listeria monocytogenes on fresh and frozen strawberries. Int. J. Food Microbiol. 101, 255-262. doi: 10.1016/j.ijfoodmicro.2004.11.010

Fongaro, G., García-González, M. C., Hernández, M., Kunz, A., Barardi, C. R. M., and Rodríguez-Lázaro, D. (2017). Different behavior of enteric bacteria and viruses in clay and sandy soils after biofertilization with swine digestate. Front. Microbiol. 8:74. doi: 10.3389/fmicb.2017.00074

Food and Drug Administration (2019). Bacteriological Analytical Manual (BAM). FDA. Available at: http://www.fda.gov/food/laboratory-methodsfood/bacteriological-analytical-manual-bam (Accessed February 20, 2020).

Franz, E., Diepeningen, A. D., de van Vos, O. J., and van Bruggen, A. H. C. (2005). Effects of cattle feeding regimen and soil management type on the fate of Escherichia coli O157:H7 and Salmonella enterica serovar Typhimurium in manure, manure-amended soil, and lettuce. Appl. Environ. Microbiol. 71, 6165-6174. doi: 10.1128/AEM.71.10.6165-6174.2005 
Franz, E., Semenov, A. V., Termorshuizen, A. J., de Vos, O. J., Bokhorst, J. G., and van Bruggen, A. H. (2008). Manure-amended soil characteristics affecting the survival of E. coli O157:H7 in 36 Dutch soils. Environ. Microbiol. 10, 313-327. doi: 10.1111/j.1462-2920.2007.01453.x

Franz, E., van Hoek, A. H., Bouw, E., and Aarts, H. J. (2011). Variability of Escherichia coli $\mathrm{O} 157$ strain survival in manure-amended soil in relation to strain origin, virulence profile, and carbon nutrition profile. Appl. Environ. Microbiol. 77, 8088-8096. doi: 10.1128/AEM.00745-11

Gartley, S., Ramos, T., Nyarko, E., de Souza, T. R., Jay-Russell, M., Chen, Y., et al. (2018). Manure pathogen survey of Salmonella and shiga toxin-producing Escherichia coli in untreated poultry and cattle manure of the Mid-Atlantic Region. in (IAFP). Available at: https://iafp.confex.com/iafp/2018/onlineprogram. cgi/Paper/18447 (Accessed March 12, 2020).

Gorski, L., Parker, C. T., Liang, A., Cooley, M. B., Jay-Russell, M. T., Gordus, A. G., et al. (2011). Prevalence, distribution, and diversity of Salmonella enterica in a major produce region of California. Appl. Environ. Microbiol. 77, 2734-2748. doi: 10.1128/AEM.02321-10

Greene, S. K., Daly, E. R., Talbot, E. A., Demma, L. J., Holzbauer, S., Patel, N. J., et al. (2008). Recurrent multistate outbreak of Salmonella Newport associated with tomatoes from contaminated fields, 2005. Epidemiol. Infect. 136, 157-165. doi: 10.1017/S095026880700859X

Gruszynski, K., Pao, S., Kim, C., Toney, D., Wright, K., Ross, P. G., et al. (2014). Evaluating wildlife as a potential source of Salmonella serotype Newport (JJPX01.0061) contamination for tomatoes on the eastern shore of Virginia. Zoonoses Public Hlth 61, 202-207. doi: 10.1111/zph.12061

Gu, G., Strawn, L. K., Oryang, D. O., Zheng, J., Reed, E. A., Ottesen, A. R., et al. (2018). Agricultural practices influence Salmonella contamination and survival in pre-harvest tomato production. Front. Microbiol. 10:2451. doi: 10.3389/fmicb.2018.02451

Gu, G., Strawn, L. K., Zheng, J., Reed, E. A., and Rideout, S. L. (2019). Diversity and dynamics of Salmonella enterica in water sources, poultry litters, and field soils amended with poultry litter in a major agricultural area of Virginia. Front. Microbiol. 10:2868. doi: 10.3389/fmicb.2019.02868

Hanning, I. B., Nutt, J. d., and Ricke, S. C. (2009). Salmonellosis outbreaks in the United States due to fresh produce: sources and potential intervention measures. Foodborne Pathog. Dis. 6, 635-648. doi: 10.1089/fpd.2008.0232

Harrand, A. S., Kovac, J., Carroll, L. M., Guariglia-Oropeza, V., Kent, D. J., and Wiedmann, M. (2019). Assembly and characterization of a pathogen strain collection for produce safety applications: pre-growth conditions have a larger effect on peroxyacetic acid tolerance than strain diversity. Front. Microbiol. 10:1223. doi: 10.3389/fmicb.2019.01223

Harris, L. J., Berry, E. D., Blessington, T., Erickson, M., Jay-Russell, M., Jiang, X., et al. (2013). A framework for developing research protocols for evaluation of microbial hazards and controls during production that pertain to the application of untreated soil amendments of animal origin on land used to grow produce that may be consumed raw. J. Food Prot. 76, 1062-1084. doi: 10.4315/0362-028X.JFP-13-007

Himathongkham, S., Nuanualsuwan, S., and Riemann, H. (1999). Survival of Salmonella Enteritidis and Salmonella Typhimurium in chicken manure at different levels of water activity. FEMS Microbiol. Lett. 172, 159-163. doi: 10.1111/j.1574-6968.1999.tb13464.x

Holley, R. A., Arrus, K. M., Ominski, K. H., Tenuta, M., and Blank, G. (2006). Salmonella survival in manure-treated soils during simulated seasonal temperature exposure. J. Environ. Qual. 35, 1170-1180. doi: 10.2134/ jeq2005.0449

Hruby, C. E., Soupir, M. L., Moorman, T. B., Pederson, C., and Kanwar, R. (2018). Salmonella and fecal indicator bacteria survival in soils amended with poultry manure. Water Air Soil Pollut. 229, 1-14. doi: 10.1007/ s11270-017-3667-z

Islam, M., Morgan, J., Doyle, M. P., Phatak, S. C., Millner, P., and Jiang, X. (2004a). Fate of Salmonella enterica serovar Typhimurium on carrots and radishes grown in fields treated with contaminated manure composts or irrigation water. Appl. Environ. Microbiol. 70, 2497-2502. doi: 10.1128/ AEM.70.4.2497-2502.2004

Islam, M., Morgan, J., Doyle, M. P., Phatak, S. C., Millner, P., and Jiang, X. (2004b). Persistence of Salmonella enterica serovar Typhimurium on lettuce and parsley and in soils on which they were grown in fields treated with contaminated manure composts or irrigation water. Foodborne Pathog. Dis. 1, 27-35. doi: 10.1089/153531404772914437
Jay-Russell, M., Bell, R. L., Pettengill, J., Rivadeneira, P., Aminabadi, P., Ingram, D., et al. (2018b). Molecular characterization of Shiga toxin-producing Escherichia coli and Salmonella isolates from untreated cattle and poultry manure sources at livestock farms and composting facilities in the western United States. Abstract T3-04, presented at the International Association for Food Protection Annual Meeting, July 8-11, 2018. Salt Lake City, Utah. https://www. foodprotection.org/upl/downloads/meeting/archive/5b560c51bbced93d1490d. pdf (Accessed May 4, 2020).

Jay-Russell, M., Chen, Y., Rivadeneira, P., Pouillot, R., Aminabadi, P., Pandey, P., et al. (2018a). Prevalence and levels of shiga toxin-producing Escherichia coli and Salmonella in untreated cattle and poultry manure in the West Coast of United States. in (IAFP). Available at: https://iafp.confex.com/ iafp/2018/onlineprogram.cgi/Paper/18452 (Accessed March 12, 2020).

Jechalke, S., Schierstaedt, J., Becker, M., Flemer, B., Grosch, R., Smalla, K., et al. (2019). Salmonella establishment in agricultural soil and colonization of crop plants depend on soil type and plant species. Front. Microbiol. 10:967. doi: 10.3389/fmicb.2019.00967

Jokinen, C. C., Koot, J., Cole, L., Desruisseau, A., Edge, T. A., Khan, I. U. H., et al. (2015). The distribution of Salmonella enterica serovars and subtypes in surface water from five agricultural regions across Canada. Water Res. 76, 120-131. doi: 10.1016/j.watres.2015.02.038

Kemble, J. M., Meadows, I. M., Jennings, K. M., and Walgenbach, J. F. (2017). Southeastern 2017 Vegetable Crop Handbook. Available at: https://vtechworks. lib.vt.edu/bitstream/handle/ $10919 / 78538$ / AREC-66.pdf? sequence $=1$ \&isAllowed $=y$ (Accessed February 3, 2017).

Kenney, S. J., Anderson, G. L., Williams, P. L., Millner, P. D., and Beuchat, L. R. (2006). Migration of Caenorhabditis elegans to manure and manure compost and potential for transport of Salmonella Newport to fruits and vegetables. Int. J. Food Microbiol. 106, 61-68. doi: 10.1016/j.ijfoodmicro.2005.05.011

Kumar, G. D., Williams, R. C., Al Qublan, H. M., Sriranganathan, N., Boyer, R. R., and Eifert, J. D. (2017). Airborne soil particulates as vehicles for Salmonella contamination of tomatoes. Int. J. Food Microbiol. 243, 90-95. doi: 10.1016/j. ijfoodmicro.2016.12.006

McEgan, R., Mootian, G., Goodridge, L. D., Schaffner, D. W., and Danyluk, M. D. (2013). Predicting Salmonella populations from biological, chemical, and physical indicators in Florida surface waters. Appl. Environ. Microbiol. 79, 4094-4105. doi: 10.1128/AEM.00777-13

Natvig, E. E., Ingham, S. C., Ingham, B. H., Cooperband, L. R., and Roper, T. R. (2002). Salmonella enterica serovar Typhimurium and Escherichia coli contamination of root and leaf vegetables grown in soils with incorporated bovine manure. Appl. Environ. Microbiol. 68, 2737-2744. doi: 10.1128/ AEM.68.6.2737-2744.2002

Nyberg, K. A., Vinnerås, B., Ottoson, J. R., Aronsson, P., and Albihn, A. (2010). Inactivation of Escherichia coli O157:H7 and Salmonella Typhimurium in manure-amended soils studied in outdoor lysimeters. Appl. Soil Ecol. 46, 398-404. doi: 10.1016/j.apsoil.2010.10.004

Ongeng, D., Muyanja, C., Geeraerd, A. H., Springael, D., and Ryckeboer, J. (2011). Survival of Escherichia coli O157:H7 and Salmonella enterica serovar Typhimurium in manure and manure-amended soil under tropical climatic conditions in sub-Saharan Africa. J. Appl. Microbiol. 110, 1007-1022. doi: 10.1111/j.1365-2672.2011.04956.x

Oni, R. A., Sharma, M., and Buchanan, R. L. (2015). Survival of Salmonella enterica in dried Turkey manure and persistence on spinach leaves. J. Food Prot. 78, 1791-1799. doi: 10.4315/0362-028X.JFP-15-047

Painter, J. A., Hoekstra, R. M., Ayers, T., Tauxe, R. V., Braden, C. R., Angulo, F. J., et al. (2013). Attribution of foodborne illnesses, hospitalizations, and deaths to food commodities by using outbreak data, United States, 1998-2008. Emerg. Infect. Dis. 19, 407-415. doi: 10.3201/eid1903.111866

Parnell, T. L., Harris, L. J., and Suslow, T. V. (2005). Reducing Salmonella on cantaloupes and honeydew melons using wash practices applicable to postharvest handling, foodservice, and consumer preparation. Int. J. Food Microbiol. 99, 59-70. doi: 10.1016/j.ijfoodmicro.2004.07.014

Platz, S. (1980). Studies on survival of Salmonella typhimurium in different types of soils under outdoor climatic conditions (author's transl). Zentralbl. Bakteriol. Mikrobiol. Hyg. B 171, 256-268.

Ramos, T. M., Jay-Russell, M. T., Millner, P. D., Shade, J., Misiewicz, T., Sorge, U. S., et al. (2019). Assessment of biological soil amendments of animal origin use, research needs, and extension opportunities in organic production. Front. Sustain. Food Syst. 3:75. doi: 10.3389/fsufs.2019.00073 
Schwarz, K. R., Sidhu, J. P. S., Pritchard, D. L., Li, Y., and Toze, S. (2014). Decay of enteric microorganisms in biosolids-amended soil under wheat (Triticum aestivum) cultivation. Water Res. 59, 185-197. doi: 10.1016/j.watres.2014.03.037

Semenov, A. V., van Overbeek, L., and van Bruggen, A. H. C. (2009). Percolation and survival of Escherichia coli O157:H7 and Salmonella enterica serovar Typhimurium in soil amended with contaminated dairy manure or slurry. Appl. Environ. Microbiol. 75, 3206-3215. doi: 10.1128/AEM.01791-08

Shah, M. K., Bradshaw, R., Nyarko, E., Handy, E. T., East, C., Millner, P. D., et al. (2019). Salmonella enterica in soils amended with heat-treated poultry pellets survived longer than bacteria in unamended soils and more readily transferred to and persisted on spinach. Appl. Environ. Microbiol. 85, e00334-19. doi: 10.1128/AEM.00334-19

Sharma, M., Handy, E. T., East, C. L., Kim, S., Jiang, C., Callahan, M. T., et al. (2020). Prevalence of Salmonella and Listeria monocytogenes in nontraditional irrigation waters in the mid-Atlantic United States is affected by water type, season, and recovery method. PLoS One 15:e0229365. doi: 10.1371/journal.pone.0229365

Sharma, M., Millner, P. D., Hashem, F., Camp, M., Whyte, C., Graham, L., et al. (2016). Survival and persistence of nonpathogenic Escherichia coli and attenuated Escherichia coli $\mathrm{O} 157: \mathrm{H} 7$ in soils amended with animal manure in a greenhouse environment. J. Food Prot. 79, 913-921. doi: 10.4315/0362-028X. JFP-15-421

Sharma, M., and Reynnells, R. (2018). "Importance of soil amendments: survival of bacterial pathogens in manure and compost used as organic fertilizers" in Preharvest food safety. eds. S. Thakur and K. Kniel (Washington, DC: John Wiley \& Sons, Ltd), 159-175.

Strawn, L. K., Danyluk, M. D., Worobo, R. W., and Wiedmann, M. (2014). Distributions of Salmonella subtypes differ between two U.S. produce-growing regions. Appl. Environ. Microbiol. 80, 3982-3991. doi: 10.1128/AEM.00348-14

Strawn, L. K., Fortes, E. D., Bihn, E. A., Nightingale, K. K., Grohn, Y. T., Worobo, R. W., et al. (2013a). Landscape and meteorological factors affecting prevalence of three food-borne pathogens in fruit and vegetable farms. Appl. Environ. Microbiol. 79, 588-600. doi: 10.1128/AEM.02491-12

Strawn, L. K., Grohn, Y. T., Warchocki, S., Worobo, R. W., Bihn, E. A., and Wiedmann, M. (2013b). Risk factors associated with Salmonella and Listeria monocytogenes contamination of produce fields. Appl. Environ. Microbiol. 79, 7618-7627. doi: 10.1128/AEM.02831-13

Truitt, L. N., Vazquez, K. M., Pfuntner, R. C., Rideout, S. L., Havelaar, A. H., and Strawn, L. K. (2018). Microbial quality of agricultural water used in produce preharvest production on the eastern shore of Virginia. J. Food Prot. 81, 1661-1672. doi: 10.4315/0362-028X.JFP-18-185

Underthun, K., De, J., Gutierrez, A., Silverberg, R., and Schneider, K. R. (2018). Survival of Salmonella and Escherichia coli in two different soil types at various moisture levels and temperatures. J. Food Prot. 81, 150-157. doi: 10.4315/0362-028X.JFP-17-226
USDA (2015). Manure in organic production systems. Available at: https:// www.ams.usda.gov/sites/default/files/media/Manure\%20in\%20Organic\%20 Production\%20Systems_FINAL.pdf (Accessed March 12, 2020).

USDA (2020). USDA Organic Regulations 7 CFR 205 Subpart C. Electronic Code of Federal Regulations (eCFR). Available at: https://www.ecfr.gov/ (Accessed March 12, 2020).

Wang, D., Huber, A., Dunfield, K., Murray, K., Wu, F., and Warriner, K. (2018). Comparative persistence of Salmonella and Escherichia coli O157:H7 in loam or sandy loam soil amended with bovine or swine manure. Can. J. Microbiol. 64, 979-991. doi: 10.1139/cjm-2018-0234

Watts, D. B., Torbert, H. A., Prior, S. A., and Huluka, G. (2010). Long-term tillage and poultry litter impacts soil carbon and nitrogen mineralization and fertility. Soil Sci. Soc. Am. J. 74, 1239-1247. doi: 10.2136/sssaj2008.0415

Weller, D., Belias, A., Green, H., Roof, S., and Wiedmann, M. (2020). Landscape, water quality, and weather factors associated with an increased likelihood of foodborne pathogen contamination of New York streams used to source water for produce production. Front. Sustain. Food Syst. 3:124. doi: 10.3389/ fsufs.2019.00124

Weller, D., Wiedmann, M., and Strawn, L. K. (2015). Irrigation is significantly associated with an increased prevalence of Listeria monocytogenes in produce production environments in New York state. J. Food Prot. 78, 1132-1141. doi: 10.4315/0362-028X.JFP-14-584

Wyenandt, A., Kuhar, T., Hamilton, G., VanGessel, M., and Sanchez, E. (2016). 2016-2017 Mid-Atlantic Commercial Vegetable Production Recommendations. Available at: https://vtechworks.lib.vt.edu/bitstream/handle/10919/78580/456-420. pdf? sequence=1\&isAllowed=y (Accessed February 3, 2017).

You, Y., Rankin, S. C., Aceto, H. W., Benson, C. E., Toth, J. D., and Dou, Z. (2006). Survival of Salmonella enterica serovar Newport in manure and manure-amended soils. Appl. Environ. Microbiol. 72, 5777-5783. doi: 10.1128/ AEM.00791-06

Zibilske, L. M., and Weaver, R. W. (1978). Effect of environmental factors on survival of Salmonella Typhimurium in soil 1. J. Environ. Qual. 7, 593-597. doi: $10.2134 /$ jeq1978.00472425000700040025x

Conflict of Interest: The authors declare that the research was conducted in the absence of any commercial or financial relationships that could be construed as a potential conflict of interest.

Copyright (c) 2021 Bardsley, Weller, Ingram, Chen, Oryang, Rideout and Strawn. This is an open-access article distributed under the terms of the Creative Commons Attribution License (CC BY). The use, distribution or reproduction in other forums is permitted, provided the original author(s) and the copyright owner(s) are credited and that the original publication in this journal is cited, in accordance with accepted academic practice. No use, distribution or reproduction is permitted which does not comply with these terms. 